\title{
Application of Monoclonal Antibody Therapies in Autoimmune Diseases
}

\author{
Adrienn Angyal ${ }^{1}$, Jozsef Prechl ${ }^{2}$, Gyorgy Nagy ${ }^{3}$ and Gabriella Sarmay ${ }^{1}$ \\ ${ }^{1}$ Dept. of Immunology, Eotvos Lorand University, Budapest, \\ 2Immunology Research Group of the Hungarian Academy of Sciences, \\ at Eotvos Lorand University, Budapest, \\ ${ }^{3}$ Buda Hospital of Hospitaller Brothers of St. John, Budapest \\ Hungary
}

\section{Introduction}

A better understanding of the pathogenesis of autoimmunity makes it possible to select more specific therapeutic targets and design biological agents that can replace or enhance the effect of immunosuppressive drugs; these include monoclonal antibodies, soluble receptors and molecular mimetics. This chapter aims to give a brief summary on different protein-based medications: first on the biologicals targeting cytokines that induce inflammatory responses, then on drugs depleting B cells via CD20 and CD22 and finally, on agents that inhibit cell-cell contacts and block cell survival factors. Immunogenicity of these protein preparations causes a significant problem therefore the last section gives an overview of biotechnological approaches aiming to reduce this effect.

\section{The blockade of cytokines inducing inflammatory responses}

TNF $\alpha$-blocking agents (Etanercept, Adalimumab, Infliximab)

Currently, there are 3 major TNF $\alpha$-blockers available for patients who do not react well to standard therapies like methotrexate or other disease modifying anti-rheumatic drugs (DMARDs), these are: etanercept, infliximab and adalimumab. Most common side effects of anti-TNF $\alpha$ therapy are a higher susceptibility for infections and possible flares of TB.

Etanercept, a fusion protein consisting of two extracellular binding domains of the TNF < receptor 2 and the Fc-part of a human IgG1 molecule is acting like a soluble decoy receptor by inhibiting ligand-binding to TNF-receptors, only with an extended in vivo half-life due to the presence of the Fc-part. It is licensed by the FDA for the treatment of RA, polyarticular juvenile idiopathic arthritis (JIA), psoritic arthritis, ankylosing spondylitis and plaque psoriasis (1).

Infliximab (Remicade) is a chimeric monoclonal antibody specific for TNF $\alpha$ that was approved by the FDA in 1998 for the treatment of Crohn's disease (2). Its use has been extended since then to the treatment of psoriasis, ankylosing spondylitis, psoriatic arthritis, rheumatoid arthritis and ulcerative colitis.

Adalimumab (Humira), another monoclonal antibody of fully human origin was derived by a phage display library and used to treat RA patients first. Since then, clinical trials proved 
its effectiveness in psoriatic arthritis, ankylosing spondylitis, Crohn's disease, psoriasis and juvenile idiopathic arthritis (3).

Infliximab and adalimumab were shown to neutralize biological activity of TNF $\alpha$ by binding to its soluble, membrane- or receptor-bound forms, while etanercept is unable to neutralize the receptor-bound form of TNF $\alpha$ due to its structural features. Additionally, the anti-TNF monoclonal antibodies can induce Fc-receptor-mediated cell lysis and infliximab has been also shown to induce apoptosis of lamina propria T cells in Crohn's patients in a TNF $\alpha$-dependent manner.

In a follow-up comparative study Bacquet-Deschryver et al. evaluated the effects of the 3 different anti-TNF $\alpha$ biologics on the re-emerginig of anti-nuclear antibodies (ANA), antidsDNA antibodies, RF and anti-CCP in rheumatoid arthritis and spondyloarthropathy patients (3). They found that the response to treatment is independent of the induction of ANA production and anti-dsDNA autoantibody variations regardless of the rheumatism and the anti-TNF $\alpha$ treatment prescribed.

Another study conducted in human TNF $\alpha$ transgenic mice showed that in a strictly TNF $\alpha-$ driven model of RA the number of $\mathrm{CD}^{+}{ }^{+} \mathrm{CD} 25^{+} \mathrm{FoxP} 3^{+}$Treg cells is initially lower than in wild-type counterparts, but gets elevated during the course of the disease. This population of regulatory $\mathrm{T}$ cells is attenuated in its suppressor activity, which can be restored with either passive (infliximab treatment) or active (TNF-K immunization) TNF $\alpha$-blocking approaches. Moreover, the differentiation of a CD62L- regulatory $\mathrm{T}$ cell population is induced (4).

\section{Blockade of IL-6 (tocilizumab)}

IL-6 is a widely expressed pleiotropic cytokine, best known as main mediator of fever and acute phase reactions alongside IL-1 and TNF $\alpha$. In hepatocytes it strongly induces production of acute phase proteins e.g. C-reactive protein, mannan-binding lectin, or serum amyloid protein $\mathrm{A}$, and it also causes immobilization of neutrophil granulocytes from the bone marrow. Besides supporting B cell differentiation into antibody plasma cells, it has been shown to be essential in Th17 cell differentiation as well. The IL-6R consists of two chains, the $80-\mathrm{kDa}$ IL-6-binding subunit and the 130-kDa membrane glycoprotein gp130 that is responsible for signal transduction (5). The expression of membrane bound IL6R is restricted to only few cell types including macrophages, neutrophils, some T-cell subpopulations and hepatocytes. On the other hand, gp130 is ubiquitously expressed. IL-6R is either shed from the cell surface by matrix metalloproteases or in human, expressed as a result of alternative splicing. Association of the IL-6/sIL-6R complex to gp130 mediates agonistic signaling events (trans-signaling) (6).

Excessive levels of the IL-6/IL-6R complex can be detected in the synovial fluid of many RA patients, which could highly contribute to osteoclast-like cell formation and therefore, joint destruction (7). Also, IL-6 production of synovial fibroblasts induces excess production of vascular endothelial growth factor (VEGF) resulting in enhanced angiogenesis and increased vascular permeability of synovial tissue. Serum IL-6 levels were found elevated in other autoimmune conditions e.g. in SLE as well (8).

Tocilizumab is a humanized IL6R-specific monoclonal antibody that blocks IL-6 mediated signal transduction via the inhibition of ligand-binding to the IL-6Rs. Phase III clinical studies showed a remarkable inhibition of radiological damage of joints. It has been approved as a therapeutic drug for the treatment of RA and in Japan for Castelman's disease 
and systemic juvenile idiopathic arthritis. Tocilizumab is a potential candidate drug for the therapy of several other disorders including SLE, Crohn's disease or multiple sclerosis (9).

Inhibition of the IL-1 mediated responses with a recombinant IL-1R antagonist (anakinra)

Like TNF $\alpha$ or IL-6, IL-1 $\alpha$ and $\beta$ also induce a wide spectrum of biological responses that contribute to fight infections: these include the production of acute phase proteins, raising body temperature (hence the term endogenous pyrogens) or mobilization of neutrophils, thus promoting microbe clearance by phagocytosis. The main source for IL- $1 \alpha$ and $\beta$ are macrophages and epithelial cells, whereas IL-1Ra, a naturally occurring IL-1R antagonist is released also by monocytes and hepatocytes (10). The IL-1 receptors CD121a and b are expressed on different subsets of lymphocytes, monocytes and macrophages.

Recombinant IL-1a (anakinra) is an approved therapeutic drug for RA that mimics the effects of endogenous IL-1Ra, thus blocking the IL-1 binding site on the receptor without inducing any further signaling events. The treatment with anakinra is well tolerated, with less occurring opportunistic infections than in case of $\mathrm{TNF} \alpha$ blockage, and it was shown to improve joint swelling, pain and inflammation, although with less efficacy $(11,12,13)$.

Induction of alterations in IL-21 mediated cellular responses

IL-21 is a type I cytokine expressed by activated CD4 ${ }^{+} \mathrm{T}$ cells and NKT cells (14), and induces the differentiation and activation of NK cells, promotes NKT proliferation, enhances the differentiation of Th17 cells and was found to regulate mature B cell responses depending on the type of co-stimulation (within a wide range of inducing proliferation to cell death) (15). IL21R-/-mice showed no defects in B cell development, but had severe problems with class-switch to IgG1 and IgG2b, and the down-regulation of the germinal center reaction. As a consequence they experienced a decrease in the number of plasma cells and an increase in memory B cells (16).

Although IL-21 fulfills a complex role in the immune regulation, experimental animal models indicate that its targeting could be of therapeutic benefits. In MRL/lpr mice inhibition of IL-21 improved symptoms of the disease, the mice showing a reduction in proteinuria, skin lesions, circulating dsDNA autoantibodies and lymphadenopathy (17). In collagen-induced arthritis and in adjuvant-induced arthritis, the blockade of IL-21R with an IL-21R-Fc fusion protein reversed clinical disease activity, most probably via the downregulation of TNF $\alpha$ and production of IL-17 (18). In RA patients, IL-21R is expressed in the synovial macrophages and fibroblasts. In addition, a significantly higher percentage of IL$21 \mathrm{R}$ is to be found in the blood and synovial fluid of these individuals, where it might contribute to an increase in TNF $\alpha$ and IFN $\gamma$ secretion upon T cell activation, thus, in upregulating the pro-inflammatory response $(19,20)$.

\section{B cell depletion therapies mediated via CD20 and CD22}

While initially systemic autoimmunity was considered as a T cell-driven condition, multiple functions of B cells have been described in orchestrating autoimmune disorders, including self-reactive antibody production, auto-antigen presentation and co-stimulation of $\mathrm{T}$ lymphocytes, formation of ectopic lymphoid structures (neo-organogenesis) in the endtarget organs and pro-inflammatory cytokine production.

\section{CD20-mediated B cell depletion}

Due to their central role in the immune pathogenesis of systemic autoimmunity and the observation that patients treated with non-Hodgkin's lymphoma and coexisting RA showed 
improvements in symptoms of RA after anti-CD20 (Rituximab) treatment, several therapies target B cells.

Physiological autoimmunity, thus the production of auto-antibodies in healthy individuals emerges upon infection and facilitates the clearing of apoptotic cells at the site of inflammation. Defects in down-regulation of this response can lead to the development of pathologic conditions. One of the several criteria by the diagnosis of autoimmunity is the presence of self-reactive antibodies in the circulation that are often present decades before the onset of clinical symptoms. During the course of B cell development, many checkpoints exist to prevent the escape of self-reactive B cells to the periphery these include receptor revision, clonal deletion and anergy $(21,22)$. Once an auto-reactive B cell is activated though by a self-structure first extra-follicular short-lived plasma cells are formed that produce lowaffinity antibodies. Some of these auto-reactive cells also enter the germinal centers where they undergo affinity maturation and class switch, and develop into long-lived auto-reactive memory cells.

Antibodies can contribute to disease pathogenesis in two different ways: direct action by binding to its target e.g. in myasthenia gravis where anti-acetylcholine receptor antibodies bind post-synaptic receptors and compromise motor functions in neurons (23), or in Graves' disease, where the anti-thyroid stimulating hormone (TSH) receptor auto-antibodies can act as receptor agonists (24). The indirect contribution of auto-antibodies to autoimmunity consists of the formation of immune complexes inducing Fc-receptor mediated phagocytosis and/or activation of the complement system and production of pro-inflammatory cytokines, thus leading to tissue damage.

In addition to antibody production B cells also have an important role as antigen presenting cells. B cell deficiency in mice results in a disrupted lymphoid structure in the spleen, lack of follicular dendritic cell network and absence of Peyer's patches (25). B cell depletion studies in mice showed a defect in CD4+ T cell priming in the absence of B cell co-stimulation, especially when the antigen is available only at low concentrations. B cells not only provide support to $\mathrm{T}$ cells via direct cell-cell contact, but also shape the immune response by producing either pro-inflammatory cytokines including IL-6, IFN $\gamma$ and LT $\alpha$. Certain subsets are also able to produce IL-10 that has a regulatory function and contributes to the attenuation of the disease (26).

Tertiary ectopic lymphoid structures have been described at the end-organ in several autoimmune disorders: in the synovium of RA patients organized zones of $\mathrm{B}, \mathrm{T}$ and follicular dendritic cells can be found in more than $50 \%$ of the cases, while kidneys of SLE patients also often contain such organized structures. B cell depletion or the blockade of B cell-T cell contacts has been proved to disrupt these ectopic lymphoid follicles and attenuate disease severity in several animal models of autoimmunity (27).

One of the most effective disease modifying anti-rheumatic drugs (DMARDs) is rituximab, a human CD20-specific chimeric monoclonal antibody. CD20 is a $35-37 \mathrm{kDa}$ tetra-spanning integral membrane protein first expressed on late pre-B cells in the bone marrow, present on naïve and mature B cells, down-regulated on antibody-secreting plasmablasts and extinguishing on plasma cells. It has been shown to regulate early steps of cell cycle progression, B cell proliferation and apoptosis. Upon cell activation, it gets trans-located to membrane lipid rafts, where it can act as a $\mathrm{Ca}^{2+}$-channel (28). CD20 is also expressed on a small subset of basally activated IL1 $\beta$ - and TNF $\alpha$-producing T cells $(0.1-6.8 \%$ in healthy individuals) that showed enhanced susceptibility to apoptosis (29). Within an hour Rituximab treatment induces a $\sim 90 \%$ reduction of the pre-treatment state in circulating $\mathrm{CD} 20^{+} \mathrm{B}$ cell numbers that lasts for at least 3 months and also mediates a decrease in the 
number of resident $\mathrm{CD} 20^{+} \mathrm{B}$ cells in the damaged tissues, although with variable efficacy: $70 \%$ of cells residing in the spleen and lymph nodes are depleted after 24 hours, while access to peritoneal B cells is limited $(30,31)$. Success of the depletion also varies among B cell subpopulations: splenic marginal zone B cells, germinal center B cells and peritoneal B1 cells are significantly more protected.

The reemerging of the B cell population usually occurs in the majority of the patients after 46 months and follows a definite pattern by immature $\mathrm{CD} 5^{+} \mathrm{CD} 38^{\text {high }}$ transitional $\mathrm{B}$ cells and re-circulating plasmablasts appearing first and later circulating naïve B cells.

Monitoring of serum antibody levels in rituximab treated patients revealed that while titers of RF and anti-CCP antibodies significantly dropped, the humoral immune response towards most pathogens remained unaffected (e.g. pneumococcal capsular polysaccharide, tetanus toxoid) (32). Reduction in IgM-RF levels reflected to changes in total serum IgM levels, but the levels of IgA-RF, IgG-RF, and IgG anti-CCP antibodies decreased significantly more than those of their corresponding total serum immunoglobulin classes, which suggests that rituximab induces a selective reduction of short-lived autoantibody-secreting plasma cells. Two independent studies investigating changes in the synovial tissue composition of RA patients before and after rituximab treatment showed a significant decrease in B cell numbers in the synovium indicating that efficacy of the treatment lies in the disruption of extrafollicular lymphoid structures and the inhibition of B-T cell interactions (33).

Data about the efficacy of B cell depletion in SLE are contradictory: several studies involving only a small group of patients reported a significant clinical improvement upon rituximab treatment, while phase II/III trials showed no difference in BILAG scores. In contrast, B cell deficient lupus-prone MRL/lpr mice do not develop nephritis due to the reduced activation of the T cell compartment while transgenic mice expressing only membrane bound BCR on the cell surface (mIgM.MRL/lpr) still develop the disease (34). Another study found that mouse strains prone to develop autoimmunity are a lot more resistant to B cell depletion. These data indicate a more complex role for B cells in SLE than the production of autoreactive antibodies. CD20-mediated B cell depletion at an early age in pristane-primed NZB/W F1 mice resulted in acceleration of the onset of disease, possibly due to the lack of IL-10 production by regulatory B cells. Treatment following the outbreak of symptoms on the other hand attenuated the intensity of the disease (35).

\section{CD22-mediated B cell depletion}

Another B lymphocyte restricted target is the Ig-superfamily member CD22, a $135 \mathrm{kDa}$ glycoprotein that is first detected in the cytoplasm of pro- and pre-B cells, becoming present on the cell surface of mature peripheral B cells. It remains expressed on germinal center B cells but is absent on plasmablasts and terminally differentiated plasma cells. Known ligands of CD22 include the tyrosine phosphatase CD45 and the lectin CD33, both binding through $\alpha 2,6$-linked sialic acid motifs. While CD22 was reported to inhibit BCR-mediated cell activation in vitro via the recruitment of SHP-1 phosphatase to its cytoplasmic ITIM sequences upon phosphorylation by the tyrosine kinase Lyn (36), its in vivo role is less clarified. CD22-deficient mice develop hyper-proliferative B-lymphocytes and in consequence increased levels of auto-antibodies.

Epratuzumab, a humanized monoclonal IgG1 CD22-specific antibody recognizes a nonligand-binding site of the CD22 molecule. It is predicted to alter BCR-signaling by inducing disruption of cell surface signaling complexes and antibody-mediated depletion of B cells (37). Epratuzumab is shown to cause phosphorylation and internalization of CD22 on peripheral B cells in vitro. On a small cohort of SLE-patients, when administered four times 
every second week it was reported to improve clinical symptoms in all of the patients based on the 6-, 10- or 18-week assessments (38).

\section{Inhibition of cell-cell contacts and survival factors}

Several other monoclonal antibodies currently under clinical trial target B cell survival factors and cytokines like B-cell activating factor (BAFF), a proliferation inducing ligand (APRIL), IL-6 or IL-10.

Inhibition of the $B$ cell survival factors BAFF and APRIL

BAFF and APRIL are members of the TNF superfamily that maintain peripheral B cell- and plasma cell homeostasis by supporting cell survival. Access to BAFF modifies the stringency of negative selection of naïve B cells, as auto-reactive B cells depend more on BAFF relative to naïve mature cells. BAFF is produced by neutrophil granulocytes, monocytes, macrophages, dendritic cells and T cells as a trans-membrane protein and cleaved from the cell surface by the protease furin (39). In the serum, BAFF and APRIL are found as both homo- and hetero-trimers. The expression of receptors for soluble BAFF (BR3/BAFFR, TACI and BCMA) varies depending on the B-cell developmental stage. Highest levels of BR3/BAFFR are observed on primary and activated follicular and marginal B cells, while expression is decreased but still detectable on germinal center B cells. BR3/BAFFR is reduced or absent on antibody producing plasma cells, whereas TACI and BCMA are abundantly expressed on these cells. Memory B cells express all three BAFF-receptors. Neutralizing antibodies against BAFF cause a loss of transitional-2, marginal zone and follicular B cells in vivo, but transitional-1, B1 B cells, and plasma cells are not affected because latter cells receive survival signals by TACI as well (40).

\begin{tabular}{|c|c|c|c|}
\hline Monoclonal antibody & Type & Target molecule & Autoimmune disease \\
\hline Adalimumab (Humira) & human & TNF $\alpha$ & $\begin{array}{c}\text { RA, psoriatic arthritis, ankylosing } \\
\text { spondylitis, Crohn's disease, psoriasis, } \\
\text { juvenile idiopathic arthritis }\end{array}$ \\
\hline Belimumab (Benlysta) & human & BAFF & SLE \\
\hline $\begin{array}{l}\text { Certolizumab pegol } \\
\text { (Cimzia) }\end{array}$ & humanized & $\mathrm{TNF} \alpha$ & RA, Crohn's disease \\
\hline Epratuzumab & humanized & $\mathrm{CD} 22$ & SLE \\
\hline Intliximab (Remicade) & chimeric & $\mathrm{TNF} \alpha$ & $\begin{array}{l}\text { Crohn's disease, psoriasis, ankylosing } \\
\text { spondylitis, psoriatic arthritis, RA, } \\
\text { ulcerative colitis }\end{array}$ \\
\hline Natalizumab (Tysabri) & humanized & $\alpha 4$ integrin & Multiple sclerosis, Crohn's disease \\
\hline Rituximab (Rituxan) & chimeric & $\mathrm{CD} 20$ & RA \\
\hline Tocilizumab (Actemra) & humanized & IL-6R & RA, Castelman's disease \\
\hline
\end{tabular}

Table 1. Examples of therapeutic antibodies for the treatment of autoimmune disorders approved by the FDA 
In the serum of patients with active SLE and Sjogren's syndrome, the expression levels of soluble BAFF have been found elevated. Therefore, it is a potential target molecule in autoimmune disorders. Belimumab a humanized IgG1 monoclonal antibody blocks BAFFbinding to its receptors, thereby inhibiting the persistence of antibody producing B cells by mediating apoptotic cell death of early plasmablasts, naïve B cells and activated B cells (41) (42). Restriction of BAFF levels might facilitate the function of regulatory B cell populations. Atacicept is a fully human chimeric molecule consisting of the TACI ligand-binding extracellular domain fused to the Fc-portion of a human IgG1. It blocks both TACI- and BAFF-binding to their receptors and resulted to be successful in phase I clinical trials for the treatment of RA $(43,44,45)$.

\section{Inhibition of $B-T$ cell interactions}

For RA patients who give an inadequate response to anti-TNF $\alpha$ therapy, there is an increasing number of DMARDs that offer improvement of clinical symptoms by the inhibition of T cell-antigen presenting cell (APC) interactions.

Activation of T cells by antigens not only requires TCR-binding to the specific peptide-MHC complex on the APC, but also the ligation of co-stimulatory molecules like CD40, inducible $\mathrm{T}$ cell co-stimulator (ICOS) and CD28. Therefore, biologics that block these interactions may interfere with sufficient helper $\mathrm{T}$ cell activation and inhibit $\mathrm{B}$ cell differentiation into antibody producing plasma cells.

Abatacept is a soluble, fully human fusion protein of the extracellular domain of CTLA-4 and the hinge region, the $\mathrm{CH} 2$ and $\mathrm{CH} 3$ domains of a human IgG1 molecule. It recognizes B7 (CD80/86) with a high affinity and blocks its interaction with CD28, this way selectively inhibiting $\mathrm{T}$ cell activation. Abatacept is approved for the treatment of RA and juvenile idiopathic arthritis, and in a phase I trial it was shown to improve the clinical symptoms of psoriasis patients via the reduction of the size of the intralesional $\mathrm{T}$ cell population. Combination of abatacept with TNF $\alpha$-blockers is not advised as it increases the occurrence of infections and provides no additional benefits (11).

Although the role of ICOS in T cell signaling has not been completely resolved yet, experimental data demonstrate that ICOS/ICOSL is an important regulator of $\mathrm{T}$ cell activation. It is expressed on resting $\mathrm{T}$ cells only at low amounts, while it gets strongly upregulated upon activation. Highest level of expression is observed on $\mathrm{T}$ follicular helper cells. Blockade of ICOS/ICOSL interactions with monoclonal antibodies has been reported to improve collagen-induced arthritis and murine models of lupus (46). At the early stage of experimental autoimmune encephalomyelitis (EAE), a mouse model of sclerosis multiplex, inhibition of the ICOS/ICOSL interaction seemed to aggravate the disease, while it induced an improvement when administered at later phases (47). In glucose-6-phosphate isomerase (G6PI)-induced arthritis, early ICOSL-specific monoclonal antibody treatment resulted in significant loss of disease severity, but treatment at later stages of arthritis reduced symptoms only marginally. The number of G6PI-specific T helper cells decreased, but there was no difference in the antigen-specific antibody levels in the sera of the animals (48).

\section{Biotechnical approaches for the reduction of immunogenicity in monoclonal antibody therapies}

By the application of recombinant proteins in human medicine immunogenicity is one of the major concerns as several examples (insulin-, growth hormone-, factor VIII treatment or 
muronomab itself) had already shown us (49). The immune system may recognize these structures as foreign and develop an antibody response towards them, which may result in reduction of bioactivity. Factors like the sequence of the antibody, the secondary structure, the purity of the product, the dosage and frequency of administration, the diversity in MHC alleles within the population, the site of injection and the physical status of the individual all contribute to the outcome of the immunological response towards the protein-based medication $(50,51)$.

The clinical effects of the antibodies raised against the therapeutic protein depend on the epitope they recognize, their affinity and titer: some cause no reduction in bioactivity while others induce complications besides affecting the therapeutic benefits. These complications include increased risk of infusion reactions such as fever or rashes, pure red-cell aplasia or even cardiopulmonary and anaphylactic-like adverse events (52). In general, the emerging antibody response can inhibit the binding of the ligand to the receptor, or change the conformation and therefore the affinity and signaling properties of the soluble mediator (e.g. in case of IFN $\beta$ treatment). Immunological responses against monoclonal antibodies often enhance clearance by complex formation or block target recognition by binding to the variable region (idiotype). Rituximab, a mouse-human chimeric antibody induces the development of human anti-chimeric antibodies (HACA) in 1-5\% of Non Hodgin's lymphoma and RA patients and in $65 \%$ of SLE patients, resulting in a reduction of the efficacy of B cell depletion and often in hypersensitivity reactions $(53,54)$.

Several different techniques exist to attenuate the break-through of tolerance against monoclonal antibodies, these include:

a. The replacement of murine constant regions with human sequences, where the specificity of the antibody remains intact (chimera design)

The hybridoma technology enabled us to produce monoclonal murine antibodies in large quantities (55). On the other hand, generation of human hybridomas is difficult because they produce only small amounts of IgM and are very unstable. Recombinant DNA techniques make it possible to change the constant regions of murine immunoglobulins to human domains (56). The heavy and light chain genes are clustered into exons that represent the domain structures, which facilitates domain exchanges in antibody molecules. The vector selection is a critical step in the in vitro production of these monoclonal antibody constructs, as glycosylation patterns highly vary between species. Mammalian non-immune cells (HeLa or $\mathrm{CHO}$ cells) or certain myeloma cell lines are frequently used for this purpose. (57)

The choice of the heavy chain isotype frequently defines the mechanism of action: IgG1 is binding with high affinity to FcyRs, therefore, the therapeutic antibody of such isotype is more likely to cause additional cell depletion via antibody-dependent cellmediated cytotoxicity (ADCC). On the other hand IgG2 interacts only weakly with low affinity Fc $\gamma R$ s, so the therapeutic effects observed are mainly attributed to the capacity of the antibody for blocking or altering cellular signaling through the targeted receptor.

b. Humanization or reshaping of the variable region, thus partial exchange of framework residues to human sequences

The antigen specificity of the antibody is defined by only a few amino acids that are exposed to the surface of the antigen-binding pocket (paratope) and interact with the antigen. By transferring this set of residues from a nonhuman origin to a human frame (FR), the specificity of the antibody should remain (58). 
The engrafting of the complementary determining regions (CDR) consists of different steps: the determination of the sequences in the nonhuman antibody that participate in the specific recognition of the antigen, the selection of the fitting human frame to engraft it in, and finally, the assembly of the nonhuman CDR and the human FR to a functional antibody via the insertion of back mutations. In order to minimize the presence of nonhuman sequences within the humanized antibody construct, several methods e.g. specificity determining residue (SDR) engrafting or superhumanization had been proposed. While the first is based on the computational analysis of the three-dimensional structure of the antigen-antibody complex, suggesting that only $20-33 \%$ of CDR residues are in contact with the antigen, the latter relies on the in silico selection of the best matching canonical structures of both the nonhuman and human sequences $(59,60)$.

For the engraftment, most frequently human germline sequences are used to minimize potential immunogenicity (61). The objective of the back mutations by establishing the functional antibody is to maintain, or if possible, even improve the affinity of the antibody. To obtain this several methods exist, such as e.g. error-prone PCR with low fidelity polymerases under nonstandard conditions or pooling random DNA fragments after digestion of the variable region with DNase I $(62,63)$.

Despite the fact that humanized antibodies retain less than $5 \%$ of the murine sequences, a significant anti-drug response can still be observed in $0.1-9 \%$ of the treated patients $(64,65,66)$.

c. Selection of human antibody $\mathrm{V}$ regions using a phage library screen based on the affinity towards the antigen.

Besides attempts to avoid immunogenicity, antigen display also provides the best method to overcome limitations of the hybridoma technology concerning toxic or highly conserved antigen structures. Several display systems that apply insertion of variable region fragments to the phage genome have been developed for phage T7 (67), phage $\lambda(68,69,70)$ and the Ff class (genus Inovirus) of the filamentous phage $\mathrm{f1}, \mathrm{fd}$, and M13 (71). The source for antibody fragments can either be a naive, a semi-synthetic or an entirely synthetic library. Naive libraries are generated by mRNA isolation and cDNA synthesis from B cells (naïve or antigen exposed cells), and the variable region genes are either expressed separately with a two or three step cloning strategy or fused as an $\mathrm{ScFv}$ in a polymerase chain reaction (PCR). If the assembly PCR is involving randomization of the CDR3 region, namely the usage of oligonucleotide primers encoding various CDR3 and J gene segments (72), a semi-synthetic library is established. Entirely synthetic libraries use various different $V_{H}$ and $V_{L}$ germline master frameworks, combined with synthetically created CDR cassettes.

The pIII minor coat protein of the filamentous phage M13 is widely used to fuse the antibody fragment of interest with, thus resulting in the expression of the antibody fragment on the surface of the phage. High affinity binding constructs can be then selected by panning, a method that consists of incubation cycles (2-5) with surfacebound antigen, followed by a restricting washing to remove non-specific clones. Specificity of selected constructs can be evaluated then using enzyme-linked immunosorbent assay (ELISA).

As a final step for the generation of therapeutic antibodies, the selected variable region genes need to be inserted into a human frame sequence.

Clinical data show that despite the fully human sequence, many of the monoclonal antibodies produced by phage display technology e.g. the TNF $\alpha$-specific adalimumab 
are still immunogenic (73). An explanation for this could be that in vitro affinity maturation lacks several control steps, as there is an additional in vivo selection for attributes such as stability and aggregation besides molecular recognition.

d. Human antibody production of transgenic mice expressing human immunoglobulin genes

Strategies to establish mouse strains with germ line modifications in their immunoglobulin genes usually aim for homologous recombination in mouse embryonic stem cells that disrupt endogenous Ig heavy and light chains, and introduce the human transgenes. In the past, different technologies were successfully applied to produce and deliver the human sequence transgenes: Lonberg et al. used pronuclear microinjection to introduce reconstructed minilocus transgenes (74), while Green et al. established transgenes with yeast artificial chromosome (YAC) (75). Initially, mouse heavy and $\kappa$ light chain sequences were 'replaced' for several different $\mathrm{V}_{\mathrm{H}}, \mathrm{D}_{\mathrm{H}}$ and $\mathrm{J}_{\mathrm{H}}$ regions with $\gamma 1, \mu$ or $\delta$ heavy chain constant region fragments and $V_{\kappa}$, all five $J_{\kappa}$ and the $C_{\kappa}$ light chain genes. These transgenic animals were able to mount human antibodies in response to a targeted antigen.

There have been many initiatives undertaken since then to broaden the size of the Vregion repertoire, as it has a strong influence on multiple checkpoints in B cell development and therefore the size of the mature B cell population (76). Following selection of the most efficient clones, for large-scale production usually a recombinant expression system is established to reduce costs (77).

In contrast to chimeric, humanized or in vitro generated therapeutic monoclonal antibodies, there are no reported cases of the generation of anti-human Ig responses towards transgenic therapeutic antibodies. Table 1 summarizes the currently available monoclonal constructs and their origin.

\section{Conclusions}

Since the development of the hybridoma technique several monoclonal antibodies have been approved for the treatment of autoimmune diseases. Immunogenicity of murine sequences caused initial complications, which could be attenuated and finally overcome by the production of chimeric and humanized antibodies and with the generation of transgenic mouse strains for human Ig-sequences. One of the crucial steps by the design of a monoclonal antibody for therapeutic applications is the selection of the right target molecule. In autoimmune disorders several options exist: the blockade of the proinflammatory cytokines TNF $\alpha$, IL-1 or IL-6, the inhibition of T cell-B cell interactions, B cell depletion to reduce autoantibody production and the establishment of ectopic lymphoid structures or the blockade of B cell survival factors. Although we still need to face adverse events upon the application of these therapeutic antibodies, targeting specific molecules will help us to reduce the severity of occurring side effects and provide more efficient medications.

\section{Acknowledgement}

This work was supported by a grant from the Research and Technology Innovation Fund (KTIA-OTKA 80689) and the National Innovation Office (NIH)-ANR bilateral grant. 


\section{References}

[1] Sethi, G., B. Sung, A. B. Kunnumakkara, and B. B. Aggarwal. 2009. Targeting TNF for Treatment of Cancer and Autoimmunity. Adv Exp Med Biol 647: 37-51.

[2] Colombel, J. F., E. V. J. Loftus, W. J. Tremaine, L. J. Egan, W. S. Harmsen, C. D. Schleck, A. R. Zinsmeister, and W. J. Sandborn. 2004. The safety profile of infliximab in patients with Crohn's disease: the Mayo clinic experience in 500 patients. Gastroenterology 126: 19-31.

[3] Bacquet-Deschryver, H., F. Jouen, M. Quillard, J. F. Menard, V. Goeb, T. Lequerre, O. Mejjad, A. Daragon, F. Tron, X. Le Loet, and O. Vittecoq. 2008. Impact of three antiTNFalpha biologics on existing and emergent autoimmunity in rheumatoid arthritis and spondylarthropathy patients. J Clin Immunol 28: 445-455.

[4] Biton, J., L. Semerano, L. Delavallee, D. Lemeiter, M. Laborie, G. Grouard-Vogel, M. C. Boissier, and N. Bessis. 2011. Interplay between TNF and Regulatory T Cells in a TNF-Driven Murine Model of Arthritis. J Immunol

[5] Hibi, M., M. Murakami, M. Saito, T. Hirano, T. Taga, and T. Kishimoto. 1990. Molecular cloning and expression of an IL-6 signal transducer, gp130. Cell 63: 1149-1157.

[6] Kishimoto, T. 2005. Interleukin-6: from basic science to medicine--40 years in immunology. Annu Rev Immunol 23: 1-21.

[7] Nishimoto, N., K. Terao, T. Mima, H. Nakahara, N. Takagi, and T. Kakehi. 2008. Mechanisms and pathologic significances in increase in serum interleukin-6 (IL-6) and soluble IL-6 receptor after administration of an anti-IL-6 receptor antibody, tocilizumab, in patients with rheumatoid arthritis and Castleman disease. Blood 112: 3959-3964.

[8] Grondal, G., I. Gunnarsson, J. Ronnelid, S. Rogberg, L. Klareskog, and I. Lundberg. 2000. Cytokine production, serum levels and disease activity in systemic lupus erythematosus. Clin Exp Rheumatol 18: 565-570.

[9] Tanaka, T., M. Narazaki, and T. Kishimoto. 2011. Anti-interleukin-6 receptor antibody, tocilizumab, for the treatment of autoimmune diseases. FEBS Lett

[10] Hannum, C. H., C. J. Wilcox, W. P. Arend, F. G. Joslin, D. J. Dripps, P. L. Heimdal, L. G. Armes, A. Sommer, S. P. Eisenberg, and R. C. Thompson. 1990. Interleukin-1 receptor antagonist activity of a human interleukin-1 inhibitor. Nature 343: 336-340.

[11] Smolen, J. S., D. Aletaha, M. Koeller, M. H. Weisman, and P. Emery. 2007. New therapies for treatment of rheumatoid arthritis. Lancet 370: 1861-1874.

[12] O'Dell, J. R. 2004. Therapeutic strategies for rheumatoid arthritis. N Engl J Med 350: 2591-2602.

[13] Goldbach-Mansky, R. 2009. Blocking interleukin-1 in rheumatic diseases. Ann N Y Acad Sci 1182: 111-123.

[14] Coquet, J. M., K. Kyparissoudis, D. G. Pellicci, G. Besra, S. P. Berzins, M. J. Smyth, and D. I. Godfrey. 2007. IL-21 is produced by NKT cells and modulates NKT cell activation and cytokine production. J Immunol 178: 2827-2834.

[15] Leonard, W. J., and R. Spolski. 2005. Interleukin-21: a modulator of lymphoid proliferation, apoptosis and differentiation. Nat Rev Immunol 5: 688-698.

[16] Ozaki, K., R. Spolski, C. G. Feng, C. F. Qi, J. Cheng, A. Sher, H. C. r. Morse, C. Liu, P. L. Schwartzberg, and W. J. Leonard. 2002. A critical role for IL-21 in regulating immunoglobulin production. Science 298: 1630-1634. 
[17] Herber, D., T. P. Brown, S. Liang, D. A. Young, M. Collins, and K. DunussiJoannopoulos. 2007. IL-21 has a pathogenic role in a lupus-prone mouse model and its blockade with IL-21R.Fc reduces disease progression. J Immunol 178: 3822-3830.

[18] Young, D. A., M. Hegen, H. L. Ma, M. J. Whitters, L. M. Albert, L. Lowe, M. Senices, P. W. Wu, B. Sibley, Y. Leathurby, T. P. Brown, C. Nickerson-Nutter, J. C. J. Keith, and M. Collins. 2007. Blockade of the interleukin-21/interleukin-21 receptor pathway ameliorates disease in animal models of rheumatoid arthritis. Arthritis Rheum 56: 1152-1163.

[19] Li, J., W. Shen, K. Kong, and Z. Liu. 2006. Interleukin-21 induces T-cell activation and proinflammatory cytokine secretion in rheumatoid arthritis. Scand J Immunol 64: 515-522.

[20] Jungel, A., J. H. Distler, M. Kurowska-Stolarska, C. A. Seemayer, R. Seibl, A. Forster, B. A. Michel, R. E. Gay, F. Emmrich, S. Gay, and O. Distler. 2004. Expression of interleukin-21 receptor, but not interleukin-21, in synovial fibroblasts and synovial macrophages of patients with rheumatoid arthritis. Arthritis Rheum 50: 1468-1476.

[21] Monroe, J. G., and K. Dorshkind. 2007. Fate decisions regulating bone marrow and peripheral B lymphocyte development. Adv Immunol 95: 1-50.

[22] von Boehmer, H., and F. Melchers. 2010. Checkpoints in lymphocyte development and autoimmune disease. Nat Immunol 11: 14-20.

[23] Ruff, R. L., and V. A. Lennon. 2008. How myasthenia gravis alters the safety factor for neuromuscular transmission. J Neuroimmunol 201-202: 13-20.

[24] Brown, R. S. 2009. Autoimmune thyroid disease: unlocking a complex puzzle. Curr Opin Pediatr 21: 523-528.

[25] Ngo, V. N., R. J. Cornall, and J. G. Cyster. 2001. Splenic T zone development is B cell dependent. J Exp Med 194: 1649-1660.

[26] Yanaba, K., J. D. Bouaziz, K. M. Haas, J. C. Poe, M. Fujimoto, and T. F. Tedder. 2008. A regulatory $\mathrm{B}$ cell subset with a unique CD1dhiCD5+ phenotype controls $\mathrm{T}$ celldependent inflammatory responses. Immunity 28: 639-650.

[27] Weyand, C. M., Y. M. Kang, P. J. Kurtin, and J. J. Goronzy. 2003. The power of the third dimension: tissue architecture and autoimmunity in rheumatoid arthritis. Curr Opin Rheumatol 15: 259-266.

[28] Tedder, T. F., and P. Engel. 1994. CD20: a regulator of cell-cycle progression of B lymphocytes. Immunol Today 15: 450-454.

[29] Wilk, E., T. Witte, N. Marquardt, T. Horvath, K. Kalippke, K. Scholz, N. Wilke, R. E. Schmidt, and R. Jacobs. 2009. Depletion of functionally active CD20+ T cells by rituximab treatment. Arthritis Rheum 60: 3563-3571.

[30] Hamaguchi, Y., J. Uchida, D. W. Cain, G. M. Venturi, J. C. Poe, K. M. Haas, and T. F. Tedder. 2005. The peritoneal cavity provides a protective niche for B1 and conventional B lymphocytes during anti-CD20 immunotherapy in mice. J Immunol 174: 4389-4399.

[31] Uchida, J., Y. Hamaguchi, J. A. Oliver, J. V. Ravetch, J. C. Poe, K. M. Haas, and T. F. Tedder. 2004. The innate mononuclear phagocyte network depletes B lymphocytes through Fc receptor-dependent mechanisms during anti-CD20 antibody immunotherapy. J Exp Med 199: 1659-1669. 
[32] Bingham, C. O. r., R. J. Looney, A. Deodhar, N. Halsey, M. Greenwald, C. Codding, B. Trzaskoma, F. Martin, S. Agarwal, and A. Kelman. 2010. Immunization responses in rheumatoid arthritis patients treated with rituximab: results from a controlled clinical trial. Arthritis Rheum 62: 64-74.

[33] Lund, F. E., and T. D. Randall. 2010. Effector and regulatory B cells: modulators of CD4(+) T cell immunity. Nat Rev Immunol 10: 236-247.

[34] Chan, O. T., L. G. Hannum, A. M. Haberman, M. P. Madaio, and M. J. Shlomchik. 1999. A novel mouse with B cells but lacking serum antibody reveals an antibodyindependent role for B cells in murine lupus. J Exp Med 189: 1639-1648.

[35] Haas, K. M., R. Watanabe, T. Matsushita, H. Nakashima, N. Ishiura, H. Okochi, M. Fujimoto, and T. F. Tedder. 2010. Protective and pathogenic roles for B cells during systemic autoimmunity in NZB/W F1 mice. J Immunol 184: 4789-4800.

[36] Carnahan, J., P. Wang, R. Kendall, C. Chen, S. Hu, T. Boone, T. Juan, J. Talvenheimo, S. Montestruque, J. Sun, G. Elliott, J. Thomas, J. Ferbas, B. Kern, R. Briddell, J. P. Leonard, and A. Cesano. 2003. Epratuzumab, a humanized monoclonal antibody targeting CD22: characterization of in vitro properties. Clin Cancer Res 9: 3982S3990 S.

[37] Carnahan, J., R. Stein, Z. Qu, K. Hess, A. Cesano, H. J. Hansen, and D. M. Goldenberg. 2007. Epratuzumab, a CD22-targeting recombinant humanized antibody with a different mode of action from rituximab. Mol Immunol 44: 1331-1341.

[38] Dorner, T., J. Kaufmann, W. A. Wegener, N. Teoh, D. M. Goldenberg, and G. R. Burmester. 2006. Initial clinical trial of epratuzumab (humanized anti-CD22 antibody) for immunotherapy of systemic lupus erythematosus. Arthritis Res Ther 8: R74.

[39] Bodmer, J. L., P. Schneider, and J. Tschopp. 2002. The molecular architecture of the TNF superfamily. Trends Biochem Sci 27: 19-26.

[40] O'Connor, B. P., V. S. Raman, L. D. Erickson, W. J. Cook, L. K. Weaver, C. Ahonen, L. L. Lin, G. T. Mantchev, R. J. Bram, and R. J. Noelle. 2004. BCMA is essential for the survival of long-lived bone marrow plasma cells. J Exp Med 199: 91-98.

[41] Furie, R., W. Stohl, E. M. Ginzler, M. Becker, N. Mishra, W. Chatham, J. T. Merrill, A. Weinstein, W. J. McCune, J. Zhong, W. Cai, and W. Freimuth. 2008. Biologic activity and safety of belimumab, a neutralizing anti-B-lymphocyte stimulator (BLyS) monoclonal antibody: a phase I trial in patients with systemic lupus erythematosus. Arthritis Res Ther 10: R109.

[42] Stohl, W., J. L. Scholz, and M. P. Cancro. 2011. Targeting BLyS in rheumatic disease: the sometimes-bumpy road from bench to bedside. Curr Opin Rheumatol 23: 305-310.

[43] Seyler, T. M., Y. W. Park, S. Takemura, R. J. Bram, P. J. Kurtin, J. J. Goronzy, and C. M. Weyand. 2005. BLyS and APRIL in rheumatoid arthritis. J Clin Invest 115: 3083-3092.

[44] Bracewell, C., J. D. Isaacs, P. Emery, and W. F. Ng. 2009. Atacicept, a novel B celltargeting biological therapy for the treatment of rheumatoid arthritis. Expert Opin Biol Ther 9: 909-919.

[45] Nestorov, I., A. Munafo, O. Papasouliotis, and J. Visich. 2008. Pharmacokinetics and biological activity of atacicept in patients with rheumatoid arthritis. J Clin Pharmacol 48: 406-417. 
[46] Nurieva, R. I., P. Treuting, J. Duong, R. A. Flavell, and C. Dong. 2003. Inducible costimulator is essential for collagen-induced arthritis. J Clin Invest 111: 701-706.

[47] Galicia, G., A. Kasran, C. Uyttenhove, K. De Swert, J. Van Snick, and J. L. Ceuppens. 2009. ICOS deficiency results in exacerbated IL-17 mediated experimental autoimmune encephalomyelitis. J Clin Immunol 29: 426-433.

[48] Matsumoto, I., H. Zhang, T. Yasukochi, K. Iwanami, Y. Tanaka, A. Inoue, D. Goto, S. Ito, A. Tsutsumi, and T. Sumida. 2008. Therapeutic effects of antibodies to tumor necrosis factor-alpha, interleukin-6 and cytotoxic T-lymphocyte antigen 4 immunoglobulin in mice with glucose-6-phosphate isomerase induced arthritis. Arthritis Res Ther 10: R66.

[49] Schellekens, H., and N. Casadevall. 2004. Immunogenicity of recombinant human proteins: causes and consequences. J Neurol 251 Suppl 2: II4-9.

[50] Hermeling, S., D. J. Crommelin, H. Schellekens, and W. Jiskoot. 2004. Structureimmunogenicity relationships of therapeutic proteins. Pharm Res 21: 897-903.

[51] Cohen, B. A., J. Oger, A. Gagnon, and G. Giovannoni. 2008. The implications of immunogenicity for protein-based multiple sclerosis therapies. J Neurol Sci 275: 717.

[52] Edwards, J. C., L. Szczepanski, J. Szechinski, A. Filipowicz-Sosnowska, P. Emery, D. R. Close, R. M. Stevens, and T. Shaw. 2004. Efficacy of B-cell-targeted therapy with rituximab in patients with rheumatoid arthritis. N Engl J Med 350: 2572-2581.

[53] Saito, K., M. Nawata, S. Iwata, M. Tokunaga, and Y. Tanaka. 2005. Extremely high titer of anti-human chimeric antibody following re-treatment with rituximab in a patient with active systemic lupus erythematosus. Rheumatology (Oxford) 44: 1462-1464.

[54] Sabahi, R., and J. H. Anolik. 2006. B-cell-targeted therapy for systemic lupus erythematosus. Drugs 66: 1933-1948.

[55] Kohler, G., and C. Milstein. 1975. Continuous cultures of fused cells secreting antibody of predefined specificity. Nature 256: 495-497.

[56] Jones, P. T., P. H. Dear, J. Foote, M. S. Neuberger, and G. Winter. 1986. Replacing the complementarity-determining regions in a human antibody with those from a mouse. Nature 321: 522-525.

[57] Whittle, N., J. Adair, C. Lloyd, L. Jenkins, J. Devine, J. Schlom, A. Raubitschek, D. Colcher, and M. Bodmer. 1987. Expression in COS cells of a mouse-human chimaeric B72.3 antibody. Protein Eng 1: 499-505.

[58] Studnicka, G. M., S. Soares, M. Better, R. E. Williams, R. Nadell, and A. H. Horwitz. 1994. Human-engineered monoclonal antibodies retain full specific binding activity by preserving non-CDR complementarity-modulating residues. Protein Eng 7: 805814.

[59] Gonzales, N. R., E. A. Padlan, R. De Pascalis, P. Schuck, J. Schlom, and S. V. Kashmiri. 2003. Minimizing immunogenicity of the SDR-grafted humanized antibody CC49 by genetic manipulation of the framework residues. Mol Immunol 40: 337-349.

[60] Tan, P., D. A. Mitchell, T. N. Buss, M. A. Holmes, C. Anasetti, and J. Foote. 2002. "Superhumanized" antibodies: reduction of immunogenic potential by complementarity-determining region grafting with human germline sequences: application to an anti-CD28. J Immunol 169: 1119-1125. 
[61] Gonzales, N. R., E. A. Padlan, R. De Pascalis, P. Schuck, J. Schlom, and S. V. Kashmiri. 2004. SDR grafting of a murine antibody using multiple human germline templates to minimize its immunogenicity. Mol Immunol 41: 863-872.

[62] Neylon, C. 2004. Chemical and biochemical strategies for the randomization of protein encoding DNA sequences: library construction methods for directed evolution. Nucleic Acids Res 32: 1448-1459.

[63] Stemmer, W. P. 1994. Rapid evolution of a protein in vitro by DNA shuffling. Nature 370: 389-391.

[64] Pendley, C., A. Schantz, and C. Wagner. 2003. Immunogenicity of therapeutic monoclonal antibodies. Curr Opin Mol Ther 5: 172-179.

[65] Hwang, W. Y., and J. Foote. 2005. Immunogenicity of engineered antibodies. Methods 36: 3-10.

[66] Bartelds, G. M., C. L. Krieckaert, M. T. Nurmohamed, P. A. van Schouwenburg, W. F. Lems, J. W. Twisk, B. A. Dijkmans, L. Aarden, and G. J. Wolbink. 2011. Development of antidrug antibodies against adalimumab and association with disease activity and treatment failure during long-term follow-up. JAMA 305: 14601468.

[67] Danner, S., and J. G. Belasco. 2001. T7 phage display: a novel genetic selection system for cloning RNA-binding proteins from cDNA libraries. Proc Natl Acad Sci U S A 98: 12954-12959.

[68] Huse, W. D., L. Sastry, S. A. Iverson, A. S. Kang, M. Alting-Mees, D. R. Burton, S. J. Benkovic, and R. A. Lerner. 1989. Generation of a large combinatorial library of the immunoglobulin repertoire in phage lambda. Science 246: 1275-1281.

[69] Mullinax, R. L., and J. A. Sorge. 2003. Preparing lambda libraries for expression of proteins in prokaryotes or eukaryotes. Methods Mol Biol 221: 271-287.

[70] Kang, A. S., T. M. Jones, and D. R. Burton. 1991. Antibody redesign by chain shuffling from random combinatorial immunoglobulin libraries. Proc Natl Acad Sci U S A 88: 11120-11123.

[71] McCafferty, J., A. D. Griffiths, G. Winter, and D. J. Chiswell. 1990. Phage antibodies: filamentous phage displaying antibody variable domains. Nature 348: 552-554.

[72] Akamatsu, Y., M. S. Cole, J. Y. Tso, and N. Tsurushita. 1993. Construction of a human Ig combinatorial library from genomic $\mathrm{V}$ segments and synthetic CDR3 fragments. J Immunol 151: 4651-4659.

[73] Aarden, L., S. R. Ruuls, and G. Wolbink. 2008. Immunogenicity of anti-tumor necrosis factor antibodies-toward improved methods of anti-antibody measurement. Curr Opin Immunol 20: 431-435.

[74] Lonberg, N., L. D. Taylor, F. A. Harding, M. Trounstine, K. M. Higgins, S. R. Schramm, C. C. Kuo, R. Mashayekh, K. Wymore, J. G. McCabe, and a. et. 1994. Antigenspecific human antibodies from mice comprising four distinct genetic modifications. Nature 368: 856-859.

[75] Green, L. L., M. C. Hardy, C. E. Maynard-Currie, H. Tsuda, D. M. Louie, M. J. Mendez, H. Abderrahim, M. Noguchi, D. H. Smith, Y. Zeng, and a. et. 1994. Antigen-specific human monoclonal antibodies from mice engineered with human Ig heavy and light chain YACs. Nat Genet 7: 13-21. 
[76] Green, L. L., and A. Jakobovits. 1998. Regulation of B cell development by variable gene complexity in mice reconstituted with human immunoglobulin yeast artificial chromosomes. J Exp Med 188: 483-495.

[77] Lonberg, N. 2005. Human antibodies from transgenic animals. Nat Biotechnol 23: 11171125. 


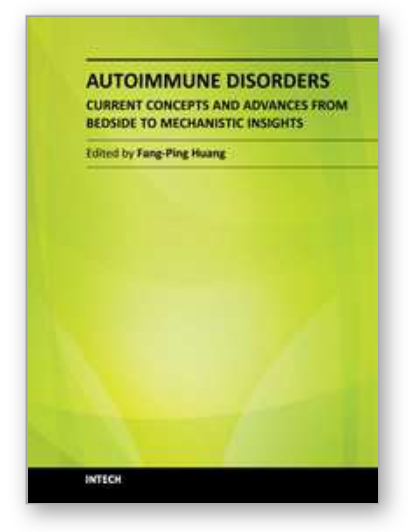

\author{
Autoimmune Disorders - Current Concepts and Advances from \\ Bedside to Mechanistic Insights \\ Edited by Dr. Fang-Ping Huang
}

ISBN 978-953-307-653-9

Hard cover, 614 pages

Publisher InTech

Published online 14, November, 2011

Published in print edition November, 2011

Autoimmune disorders are caused due to break down of the immune system, which consequently fails in its ability to differentiate "self" from "non-self" in the context of immunology. The diseases are intriguing, both clinically and immunologically, for their diversified clinical phenotypes and complex underlying immunological mechanisms. This book offers cutting-edge information on some of the specific autoimmune disease phenotypes, respective diagnostic and prognostic measures, classical and new therapeutic options currently available, pathogenesis and underlying mechanisms potentially involved, and beyond. In the form of Open Access, such information is made freely available to clinicians, basic scientists and many others who will be interested regarding current advances in the areas. Its potential readers will find many of the chapters containing in-depth analysis, interesting discussions and various thought-provoking novel ideas.

\title{
How to reference
}

In order to correctly reference this scholarly work, feel free to copy and paste the following:

Adrienn Angyal, Jozsef Prechl, Gyorgy Nagy and Gabriella Sarmay (2011). Application of Monoclonal Antibody Therapies in Autoimmune Diseases, Autoimmune Disorders - Current Concepts and Advances from Bedside to Mechanistic Insights, Dr. Fang-Ping Huang (Ed.), ISBN: 978-953-307-653-9, InTech, Available from: http://www.intechopen.com/books/autoimmune-disorders-current-concepts-and-advances-from-bedside-tomechanistic-insights/application-of-monoclonal-antibody-therapies-in-autoimmune-diseases

\section{INTECH}

open science | open minds

\section{InTech Europe}

University Campus STeP Ri

Slavka Krautzeka 83/A

51000 Rijeka, Croatia

Phone: +385 (51) 770447

Fax: +385 (51) 686166

www.intechopen.com

\section{InTech China}

Unit 405, Office Block, Hotel Equatorial Shanghai

No.65, Yan An Road (West), Shanghai, 200040, China

中国上海市延安西路65号上海国际贵都大饭店办公楼 405 单元

Phone: +86-21-62489820

Fax: $+86-21-62489821$ 
(C) 2011 The Author(s). Licensee IntechOpen. This is an open access article distributed under the terms of the Creative Commons Attribution 3.0 License, which permits unrestricted use, distribution, and reproduction in any medium, provided the original work is properly cited. 